Sādhanā Vol. 40, Part 1, February 2015, pp. 75-87. (C) Indian Academy of Sciences

\title{
Proximity fed gap-coupled half E-shaped microstrip antenna array
}

\author{
AMIT A DESHMUKH ${ }^{1, *}$ and $\mathrm{K}^{\mathrm{P}} \mathrm{RAY}{ }^{2}$ \\ ${ }^{1}$ Department of Electronics and Telecommunication Engineering, D. J. Sanghvi \\ College of Engineering, Vile -Parle (W), Mumbai 400 056, India \\ ${ }^{2}$ Society for Applied Microwave Electronics Engineering and Research, Indian \\ Institute of Technology Campus, Powai, Mumbai 400 076, India \\ e-mail: amitdeshmukh76@gmail.com; kpray@rediffmail.com
}

MS received 23 December 2013; revised 19 April 2014; accepted 24 August 2014

\begin{abstract}
Broadband gap-coupled array configuration of proximity fed rectangular microstrip antenna with half E-shaped microstrip antennas are proposed. The rectangular slot in half E-shaped patch reduces the orthogonal $\mathrm{TM}_{01}$ mode resonance frequency of equivalent rectangular patch and along with $\mathrm{TM}_{10}$ modes of fed and parasitic rectangular patches, yields broader bandwidth of more than $470 \mathrm{MHz}(>45 \%)$. An improvement in radiation pattern and gain characteristics over the bandwidth is obtained by gap-coupling half E-shaped patches along all the edges of proximity fed rectangular patch, which yields bandwidth of nearly $510 \mathrm{MHz}(\sim 49 \%)$. Further to enhance the gain, a gap-coupled $3 \times 3$ array configuration of half E-shaped patches with proximity fed rectangular microstrip antenna is proposed. The gap-coupled array configuration yields bandwidth of more than $530 \mathrm{MHz}(>50 \%)$ with broadside radiation pattern and peak gain of $11 \mathrm{dBi}$.
\end{abstract}

Keywords. Rectangular microstrip antenna; broadband microstrip antenna; half Eshaped microstrip antenna; proximity feeding; higher order mode.

\section{Introduction}

The simplest method to realize broadband microstrip antenna (MSA) is by using multi-resonator gap-coupled configuration and further by fabricating them on lower dielectric constant thicker substrate (Kumar \& Ray 2003; Garg et al 2001; Bhartia \& Bahl 1980). Due to an increase in effective aperture area, gap-coupled MSAs have higher gain. For substrate thickness, more than $0.05 \lambda_{0}$, the antenna bandwidth (BW) in multi-resonator configurations is limited by the feed probe inductance. In such cases, broader BW is realized by using proximity feeding technique which is easier to implement in thicker substrates (Cock \& Christodoulou 1987; Wong 2002). Without increasing the patch size, broadband MSA is realized by cutting the slot of different

*For correspondence 
shapes like U-slot, V-slot, rectangular slot, etc,. at an appropriate position on the edges or inside the patch (Wong 2002; Huynh \& Lee 1995; Lee et al 2010; Guo et al 1998; Weigand et al 2003). In these MSAs, slot is said to introduce a resonant mode near the fundamental mode of the patch when its length either equals half wave or quarter wave in length. The coaxial or proximity fed slot cut MSAs yield bandwidth (BW) of more than 30\% in $1000 \mathrm{MHz}$ frequency band whereas they yield BW of more than $50 \%$, when designed at frequencies above 3 to 5 GHz. A single slot cut MSA yields gain of around 6 to $8 \mathrm{dBi}$ which has been increased by using their array configurations (Wang et al 2008; Lau et al 2011). In slot cut MSA arrays, individual patch elements are fed using microstrip line power divider network which are relatively complex in design and losses in the same reduces antenna gain. By cutting pair of rectangular slots on one of the radiating edges of rectangular MSA (RMSA), an E-shaped MSA is realized (Wong \& Hsu 2001). By using its symmetry across the feed point axis, a compact half E-shaped MSA is obtained (Chair et al 2005; Deshmukh \& Kumar 2005). As compared to E-shaped MSA, half E-shaped MSA yields 50\% reduction in patch size with nearly the same BW. While designing slot cut MSAs at given frequencies, simpler approximation of slot length against wavelength, does not give closer results. An analysis of broadband $\psi$-shaped MSA is reported (Deshmukh \& Ray 2013). The $\psi$-shaped MSA is derived from E-shaped MSA by cutting an additional pair of slot on the other edge of the patch. The slots cut to realize E-shaped and further $\psi$-shaped MSA does not introduce any additional mode but it reduces the resonance frequencies of $\mathrm{TM}_{20}$ and $\mathrm{TM}_{21}$ modes of equivalent RMSA and along with its $\mathrm{TM}_{01}$ mode yields broader $\mathrm{BW}$. The $\psi-$ shaped and E-shaped MSA in $1000 \mathrm{MHz}$ frequency band yield gain of around $9 \mathrm{dBi}$ (Deshmukh $\&$ Ray 2013). To increase its gain using their gap-coupled array configuration will require larger overall patch size.

In this paper, to realize higher BW and gain, gap-coupled array configurations of proximity fed RMSA with compact half E-shaped MSAs are proposed. The proposed MSAs will not involve power divider network and use proximity feeding and gap-coupled technique, hence they are easy to implement. As compared to E-shaped MSA, half E-shaped MSA is used as it reduces the overall patch size and gives higher BW as compared to RMSA. Firstly, broadband proximity fed RMSA in $1000 \mathrm{MHz}$ frequency band and its gap-coupled configurations with parasitic RMSAs which are gap-coupled along with radiating as well as non-radiating edges are discussed. The gap-coupled proximity fed RMSAs yield BW of more than $350 \mathrm{MHz}$. To further enhance the BW, half E-shaped MSAs were gap-coupled along the edges of proximity fed RMSA. In first configuration, two half E-shaped MSAs were gap-coupled along the non-radiating edge of proximity fed RMSA whereas in second configuration, four half E-shaped MSAs were gap-coupled along all the edges of proximity fed RMSA. The analysis to study the effect of rectangular slot in half E-shaped MSA is presented. The slot reduces $\mathrm{TM}_{01}$ mode resonance frequency of equivalent RMSA and along with $\mathrm{TM}_{10}$ modes of fed and parasitic RMSAs, yields broader BW. In first configuration, BW of more than $470 \mathrm{MHz}(>45 \%)$ is obtained whereas second configuration yields $\mathrm{BW}$ of more than $500 \mathrm{MHz}(\sim 49 \%)$. The rectangular slot in half E-shape MSA modifies surface currents directions at orthogonal $\mathrm{TM}_{01}$ mode and aligns maximum amount of surface currents along the patch length, i.e., in the same direction as that of the surface currents at $\mathrm{TM}_{10}$ mode. Thereby it gives broadside radiation pattern over the $\mathrm{BW}$ with out any variations in the directions of E and H-planes. Although the increase in BW from two half E-shaped MSA configuration to four half E-shaped MSA configuration is smaller, the latter configuration shows better radiation pattern characteristics due to symmetrical structure. Both of these gap-coupled half E-shaped MSA configurations will help in gaining of more than $7 \mathrm{dBi}$ over most of the BW. Further, to enhance the gain, additional half E-shaped MSAs are gap-coupled along the diagonal axis of four gap-coupled half E-shaped MSAs, thereby realizing $3 \times 3$ array of half E-shaped 
MSAs with proximity fed RMSA. The $3 \times 3$ array yields BW of nearly $530 \mathrm{MHz}$ (> 50\%) with broadside radiation pattern and peak gain close to $11 \mathrm{dBi}$. The proposed MSAs were first optimized on air substrate (which realizes maximum radiation efficiency) using IE3D software (IE3D 2000). In first simulation an infinite ground plane is used (since it requires lesser computation time). To simulate infinite ground plane effect in the measurement, a square ground plane of side length $80 \mathrm{~cm}$ is used, which is more than six times the substrate thickness in all the directions with respect to patch edges (Kumar \& Ray 2003). The maximum size of gap-coupled antenna array is $37 \times 22 \mathrm{~cm}$. To investigate the antenna performance on finite ground plane, simulation and measurement were also carried out using finite square ground plane of side length $50 \mathrm{~cm}$, which showed closer match in terms of impedance response but with higher back lobe radiation, to that of $80 \mathrm{~cm}$ ground plane. In the following sections simulations and measured results with square ground plane of side length $50 \mathrm{~cm}$ are given. In measurements antennas were fabricated using copper plate having finite thickness (which is also considered in IE3D simulations) and were supported in air using foam spacer support which was placed towards antenna corners. The foam spacers were also used to maintain the required air gap between fed and parasitic patches. The antennas were fed using N-type connector of $0.32 \mathrm{~cm}$ inner wire diameter and antenna response was measured using $\mathrm{R} \&$ $\mathrm{S}$ vector network analyzer. The pattern was measured in minimum reflection surroundings with required minimum far field distance between reference antenna and gap-coupled array configurations.

\section{Proximity fed RMSAs}

The proximity fed RMSA is shown in figure 1(a, b). To realize larger BW thicker air substrate of $\mathrm{h}=3.0 \mathrm{~cm}\left(0.095 \lambda_{0}\right)$ is selected. The RMSA length $(\mathrm{L})$ is calculated such that its $\mathrm{TM}_{10}$ mode resonance frequency is around $950 \mathrm{MHz}$. To realize compact configuration, RMSA width (W) of $7 \mathrm{~cm}$ is selected. The coupling strip is placed below the patch at substrate thickness of $2.8 \mathrm{~cm}\left(0.09 \lambda_{0}\right)$. By optimizing strip dimensions and its position below the patch, simulated BW of $240 \mathrm{MHz}$ (24\%) is realized, whereas the measured BW is $238 \mathrm{MHz}$ (23.8\%). To further increase the BW and gain, parasitic RMSAs having different lengths along the two coordinate axis were gap-coupled along radiating as well as non-radiating edges of proximity fed RMSA, as shown in figure 1(c). This gives three resonance frequencies which can lead to three loops in the input impedance locus as shown in figure 1(d). The simulated BW is $363 \mathrm{MHz}$ $(36 \%)$ whereas the measured $\mathrm{BW}$ is $358 \mathrm{MHz}(35 \%)$. The radiation pattern over the $\mathrm{BW}$ is in the broadside direction with cross-polarization levels less than $15 \mathrm{~dB}$ as compared to that of the co-polar level. The antenna gain is more than $7 \mathrm{dBi}$ over the $\mathrm{BW}$. The resonance curve plot for optimized gap-coupled proximity fed RMSAs is shown in figure 1(e). It shows three peaks due to $\mathrm{TM}_{10}$ modes on proximity fed and parasitic RMSAs. The resonance curve also shows additional peak in higher frequency region. The surface currents at this frequency are varying along the patch width inside the parasitic RMSAs which are gap-coupled along the nonradiating edges, as shown in figure $1(\mathrm{f})$. This indicates the excitation of $\mathrm{TM}_{01}$ mode in them. Although at this frequency $\mathrm{TM}_{01}$ mode in parasitic RMSAs gap-coupled along patch length is also present but due to larger air gap the coupling to them is weak. Hence surface current variations for them are not distinctly observed. To increase the BW, this mode frequency is optimized with respect to $\mathrm{TM}_{10}$ mode frequencies of fed and parasitic RMSAs. For this, rectangular 


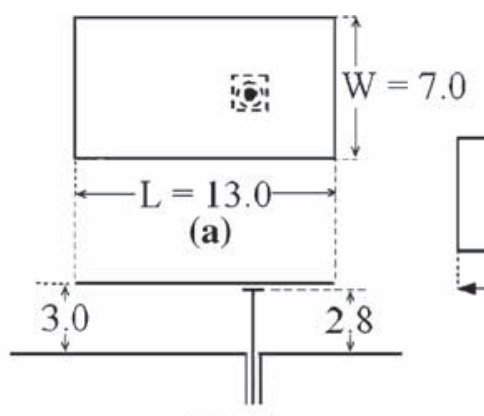

(b)

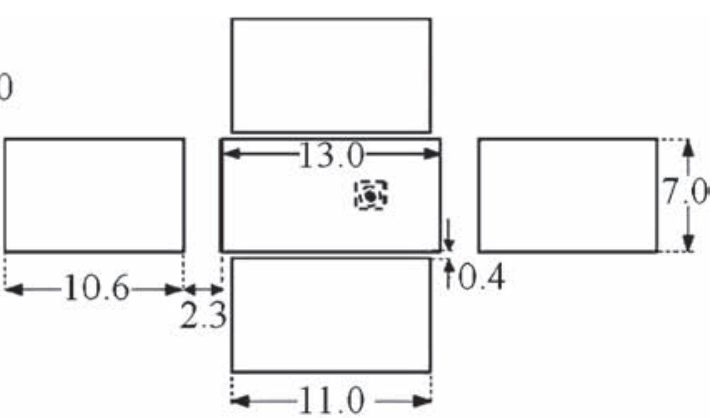

(c)

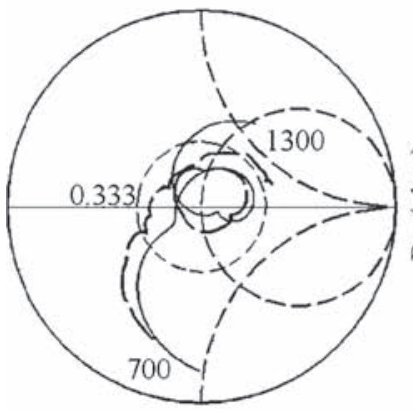

(d)
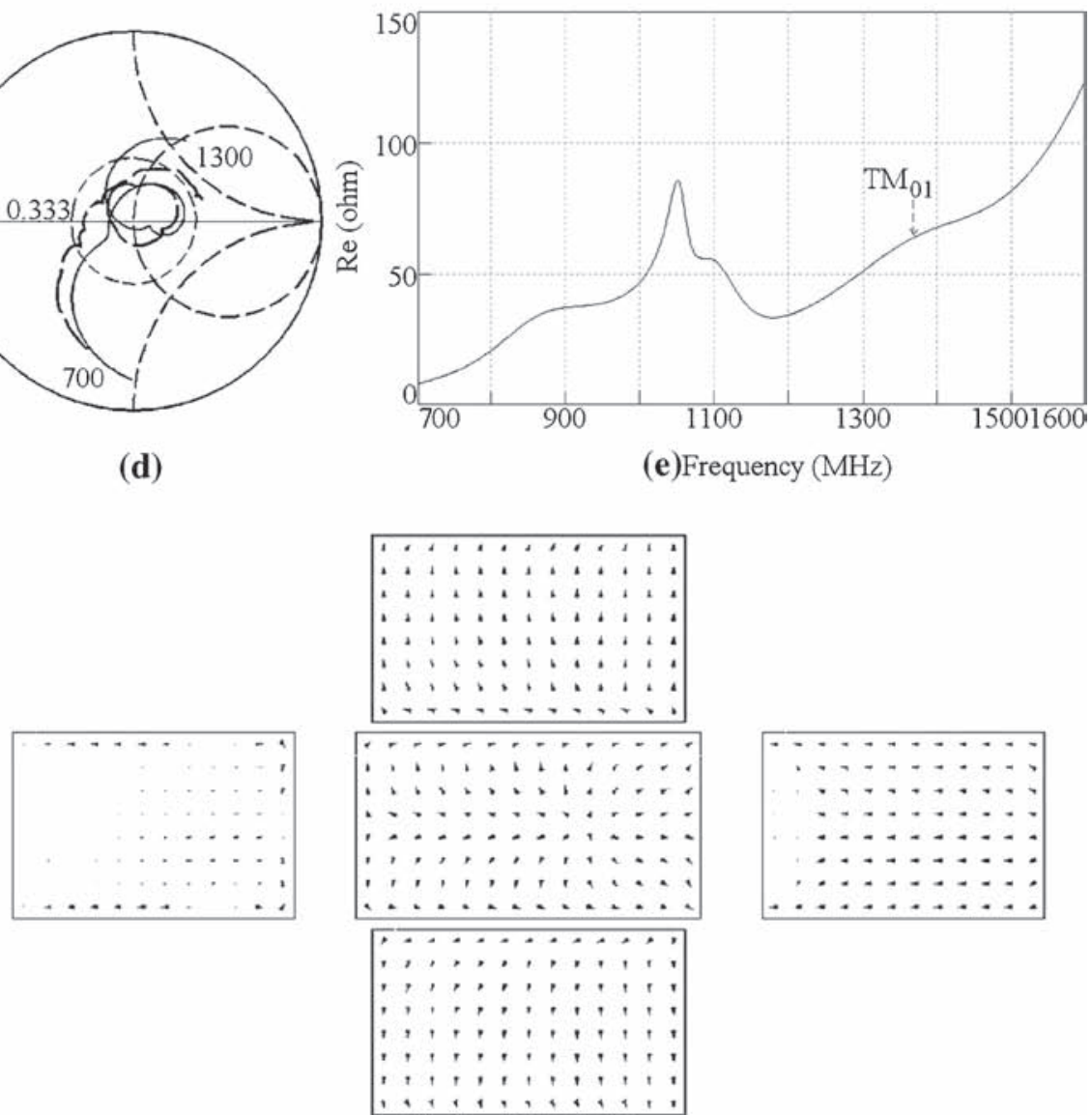

(f) $\mathrm{f}=1374 \mathrm{MHz}$

Figure 1. (a) Top view and (b) side view of proximity fed RMSA, (c) gap-coupled proximity fed RMSAs, (d) input impedance plot, (-) simulated, (- ) measured, (e) resonance curve plot and (f) surface current distribution at $\mathrm{TM}_{01}$ mode.

slot is cut on one of the radiating edges of parasitic RMSAs which were gap-coupled to the proximity fed RMSA. This realizes compact half E-shaped MSA, as discussed in the following section. 


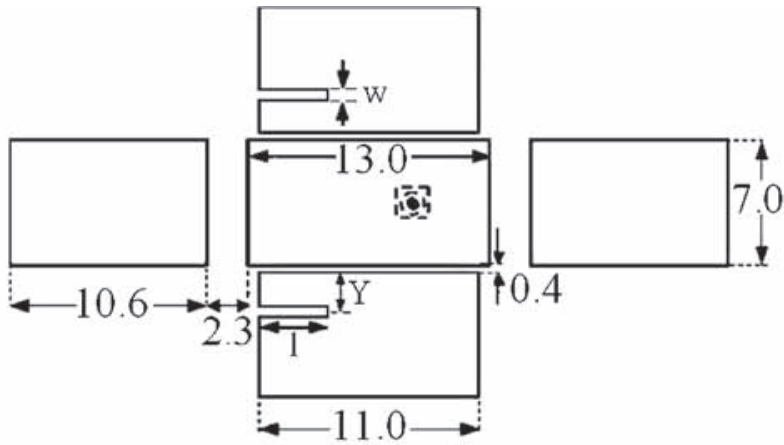

(a)

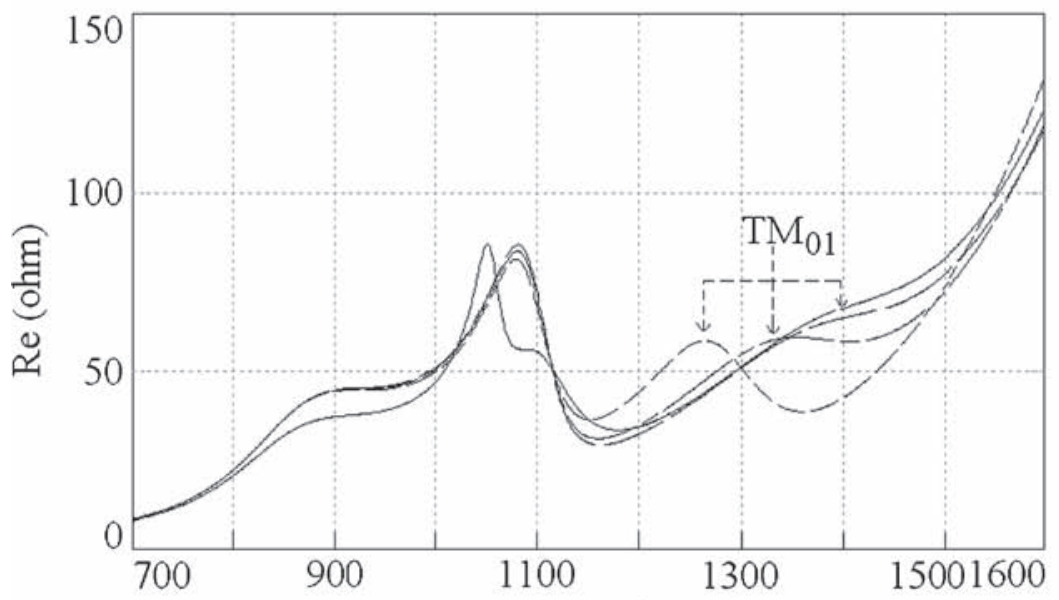

(b) Frequency $(\mathrm{MHz})$

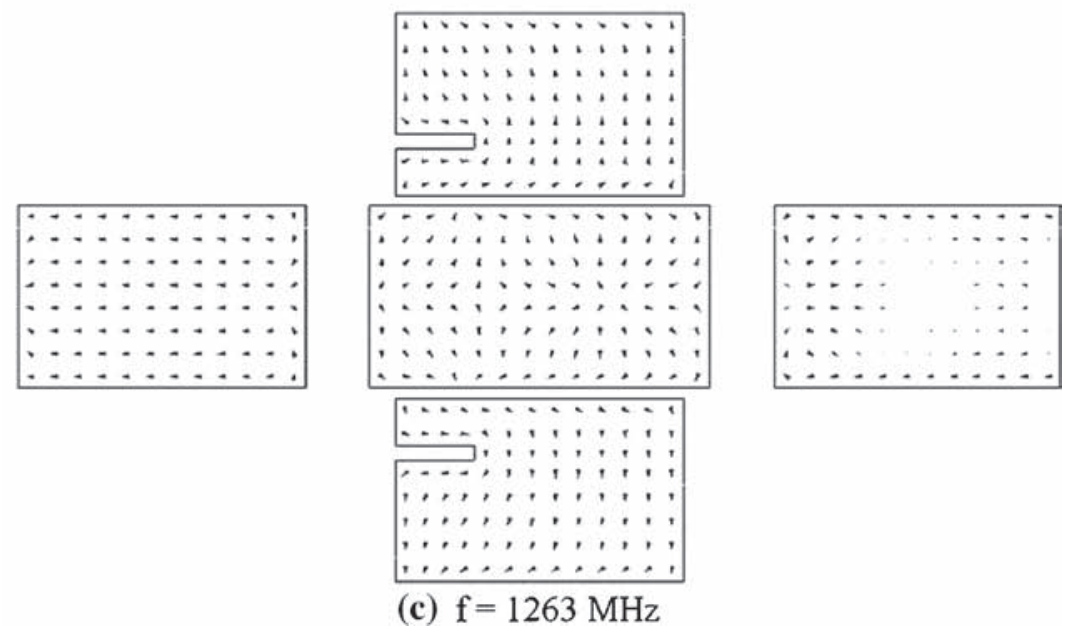

Figure 2. (a) Proximity fed RMSA gap-coupled to RMSAs and half E-shaped MSAs, (b) resonance curve plot for $1=(-) 0 \mathrm{~cm},(--) 1 \mathrm{~cm},(---) 2 \mathrm{~cm},(---) 3 \mathrm{~cm}$ and (c) surface current distribution for $1=3.0 \mathrm{~cm}$. 


\section{Broadband gap-coupled half E-shaped MSAs}

The proximity fed RMSA gap-coupled to RMSAs and half E-shaped MSAs is shown in figure 2(a). In parasitic MSAs, an equal patch and slot dimensions along the two co-ordinate axis are taken. To understand the effect of slot, slot length in half E-shaped MSA is increased in steps of $1 \mathrm{~cm}$ and for each of the case resonance curve plot, surface current distributions were studied.
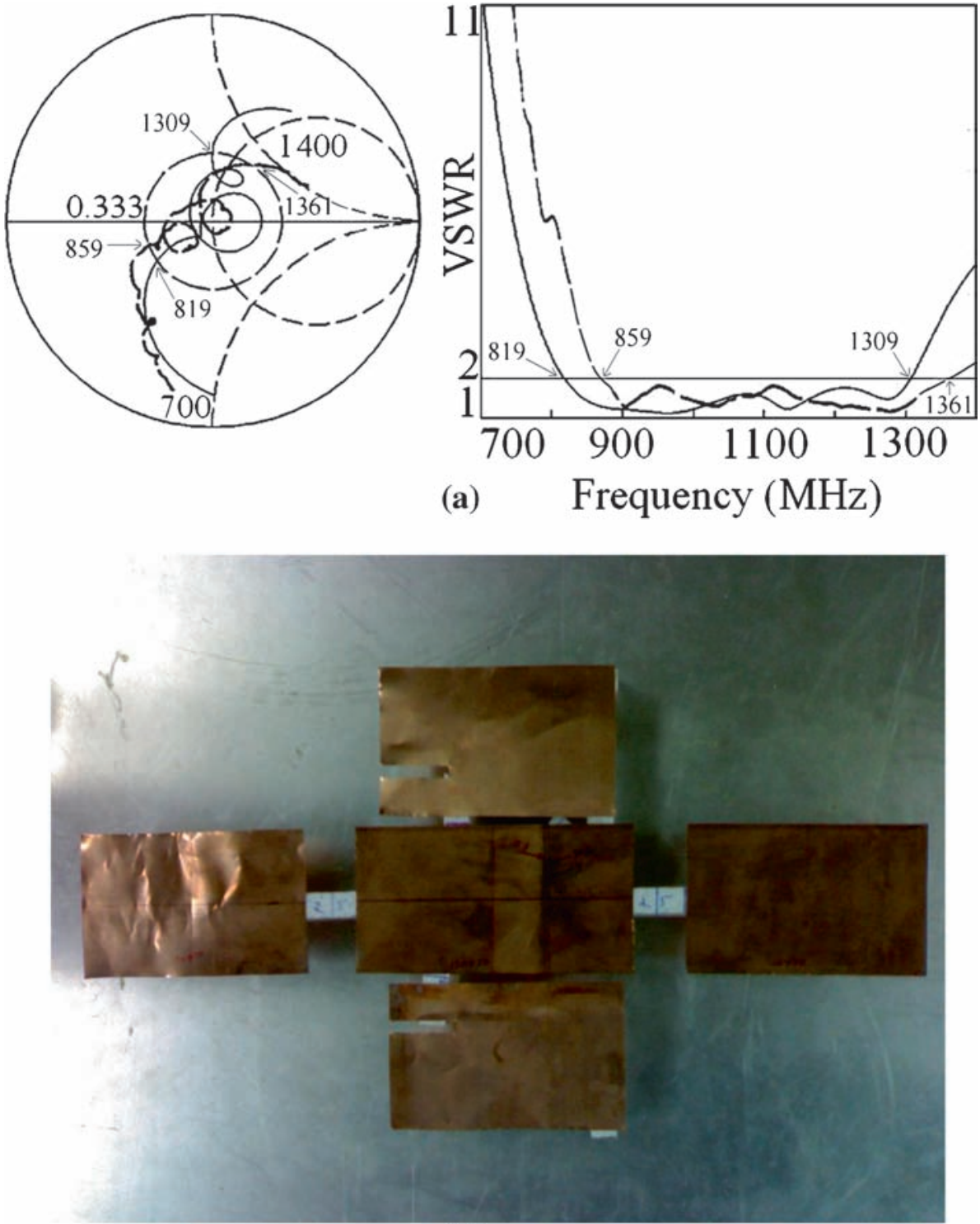

(b)

Figure 3. (a) Input impedance and VSWR plots, (--) simulated, (--) measured, (b) fabricated prototype for proximity fed RMSA gap-coupled to RMSAs and half E-shaped MSAs. 
The resonance curve plots for this variation are shown in figure 2(b). Since surface currents at $\mathrm{TM}_{01}$ mode are orthogonal to slot length, its frequency reduces with an increase in 'l' and comes closer to $\mathrm{TM}_{10}$ mode frequencies of proximity fed and gap-coupled RMSAs. The surface current distribution for $1=3.0 \mathrm{~cm}$ is shown in figure 2(c). The currents at $\mathrm{TM}_{01}$ mode are primarily directed along patch width. However, due to the rectangular slot, more and more amount of surface currents are re-oriented along the patch length. The optimum BW is realized when the loop formed due to modified $\mathrm{TM}_{01}$ mode frequency which lies inside VSWR $=2$ circle. This is obtained for slot length of $3.2 \mathrm{~cm}$. The optimized input impedance and VSWR plot on 50 $\mathrm{cm}$ ground plane is shown in figure 3(a). The simulated BW is $490 \mathrm{MHz}(48.8 \%)$ whereas the

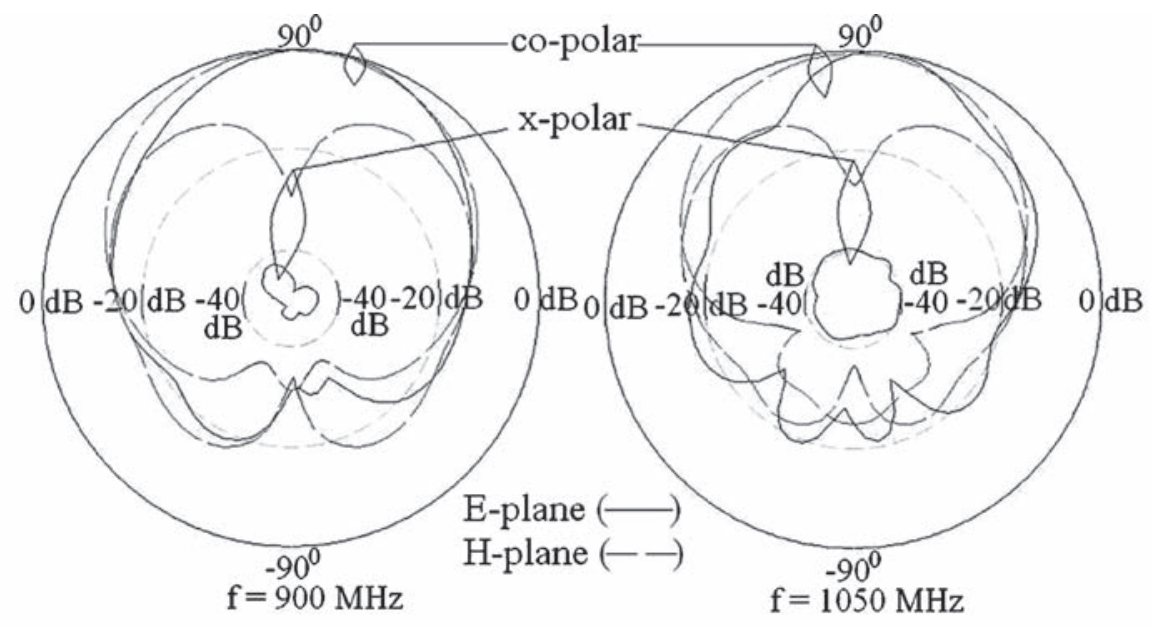

(a)

(b)

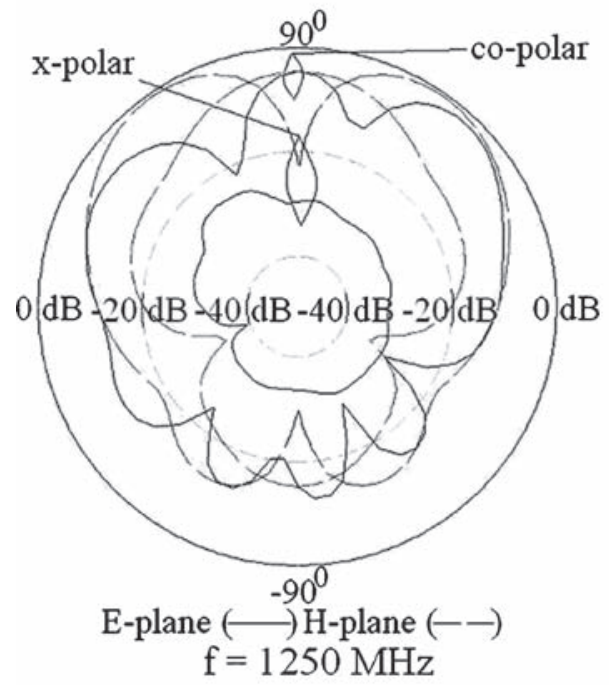

(c)

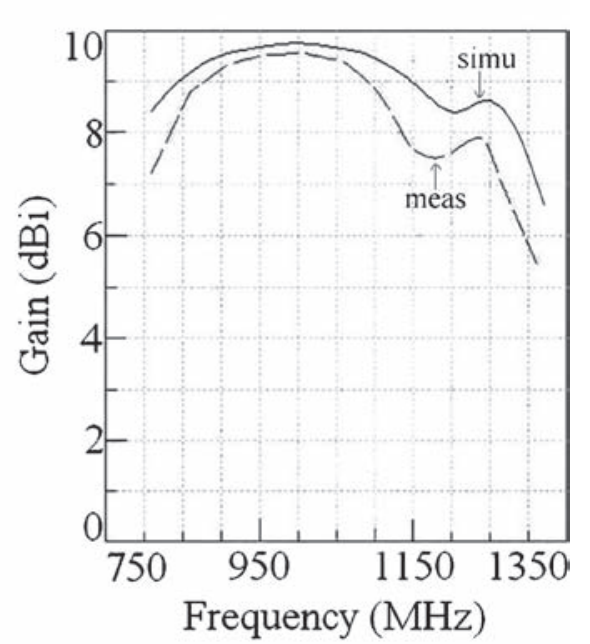

(d)

Figure 4. (a-c) Radiation pattern and (d) gain variation over BW for proximity fed RMSA gap-coupled to RMSAs and half E-shaped MSAs. 


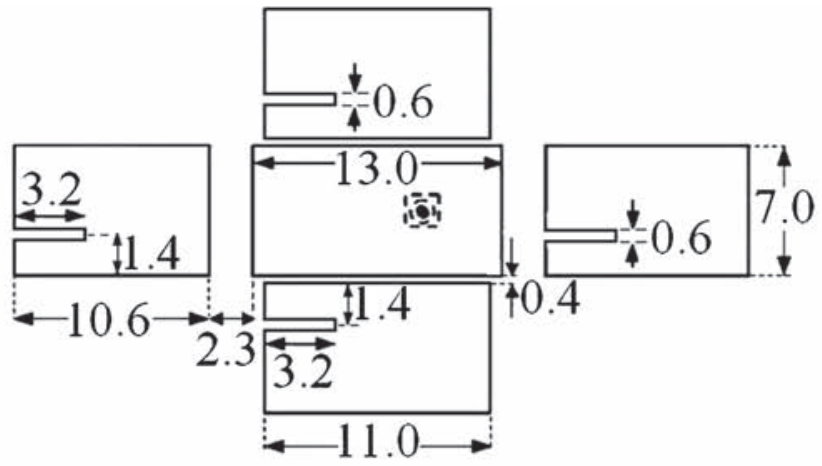

(a)
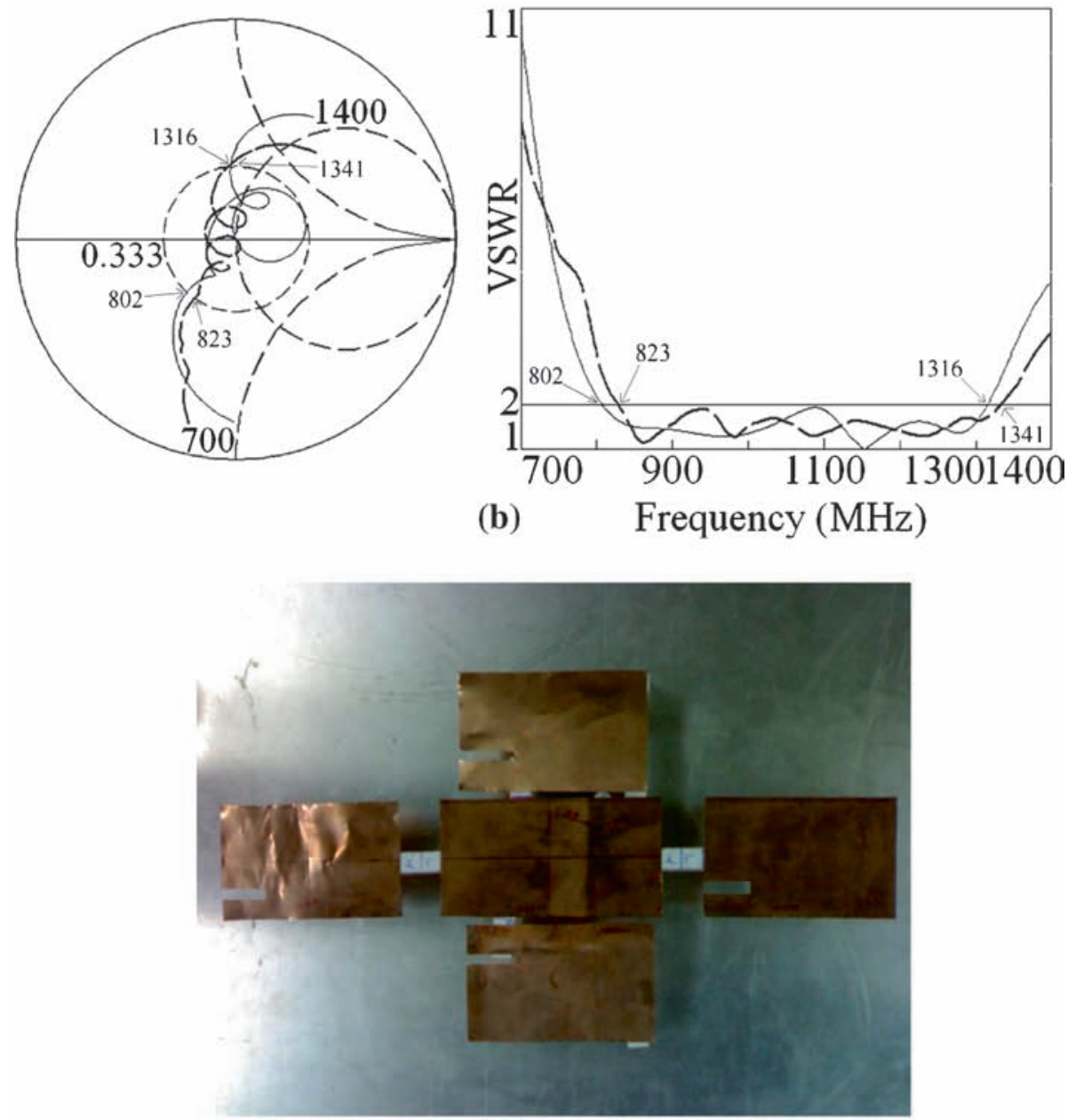

(c)

Figure 5. (a) Proximity fed RMSA gap-coupled to half E-shaped MSAs, (b) input impedance and VSWR plots, (-) simulated, (--) measured, and (c) fabricated prototype. 
measured BW is $502 \mathrm{MHz}$ (45.3\%). The fabricated prototype of the configuration is shown in figure 3(b). The measured radiation pattern and gain variation over the $\mathrm{BW}$ using $50 \mathrm{~cm}$ ground plane is shown in figure 4(a-d). The $\mathrm{E}$ and $\mathrm{H}$-planes are aligned along $\Phi=0^{0}$ and $90^{\circ}$, respectively. The pattern is in the broadside direction with cross-polarization levels less than $12 \mathrm{~dB}$ as compared to the co-polar levels. The back-lobe radiation is less than $10 \mathrm{~dB}$ as compared to the bore sight radiation. The antenna gain is more than $7 \mathrm{dBi}$ over the operating $\mathrm{BW}$ with peak gain very close to $9.5 \mathrm{dBi}$. Towards the higher frequencies of $\mathrm{BW}, \mathrm{TM}_{01}$ mode in parasitic half Eshaped MSA is dominant. This increases surface current contribution along patch width, which in turn increases cross polar levels and reduces antenna gain. To realize symmetrical structure

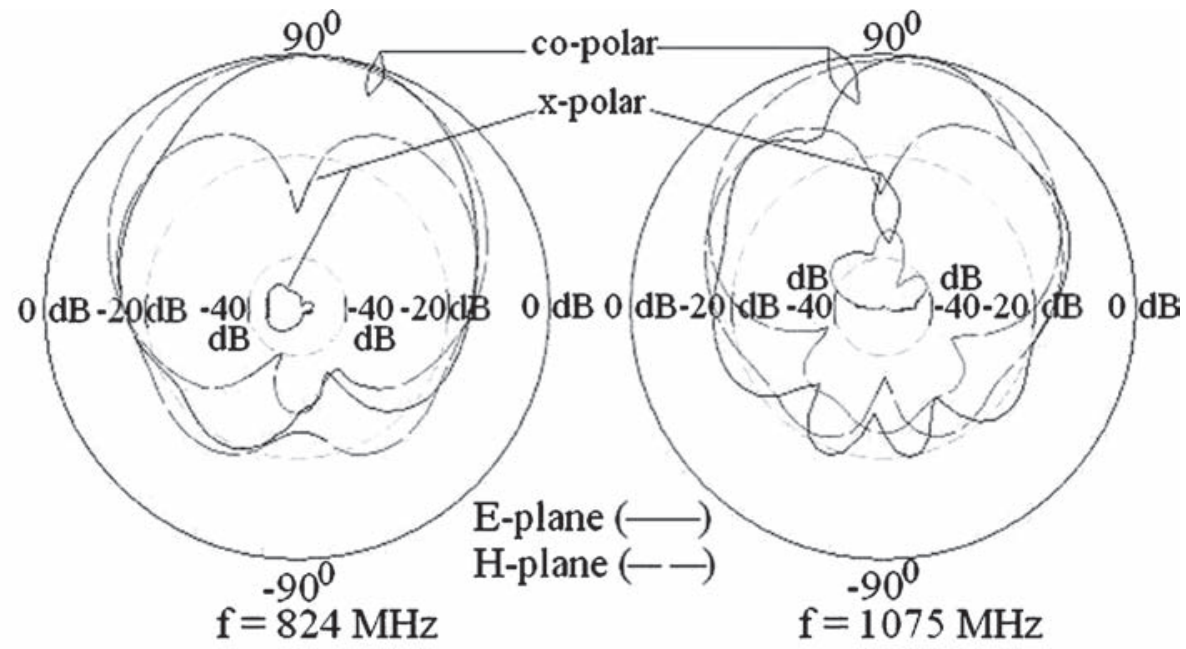

(a)

(b)

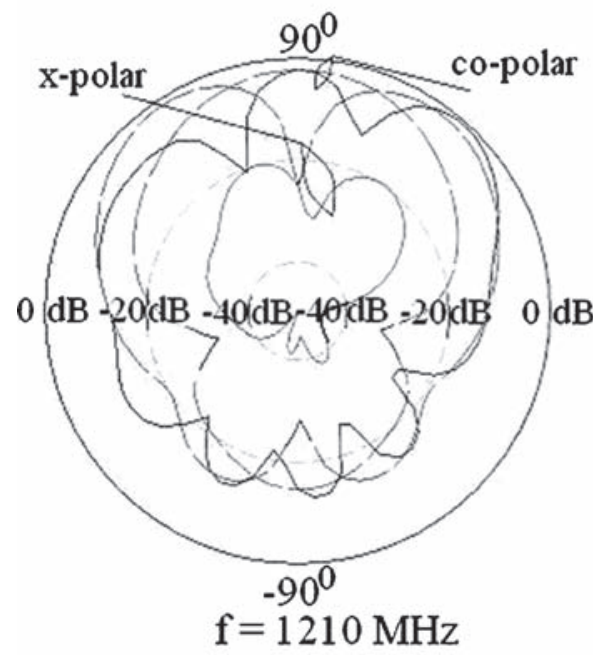

(c)

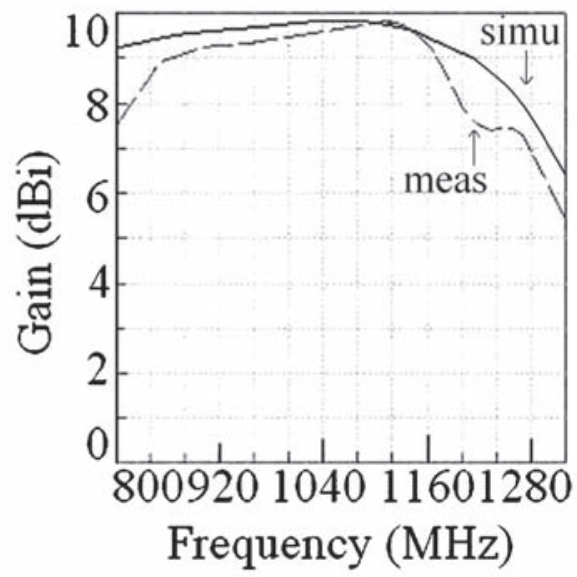

(d)

Figure 6. (a-c) Radiation pattern and (d) gain variation over BW for proximity fed RMSA gap-coupled to half E-shaped MSAs. 

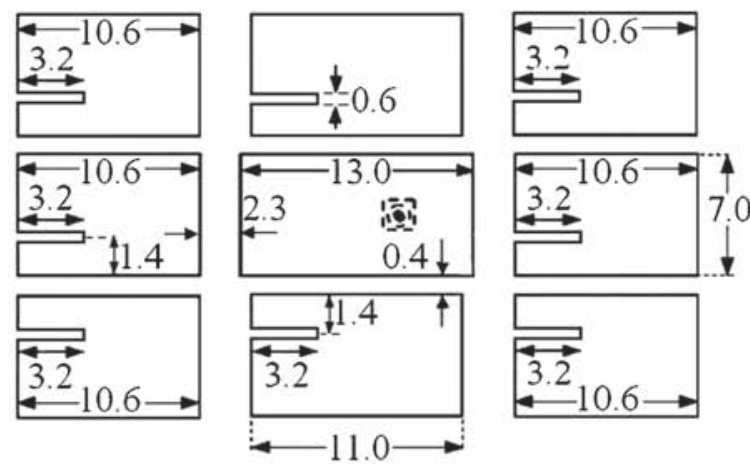

(a)
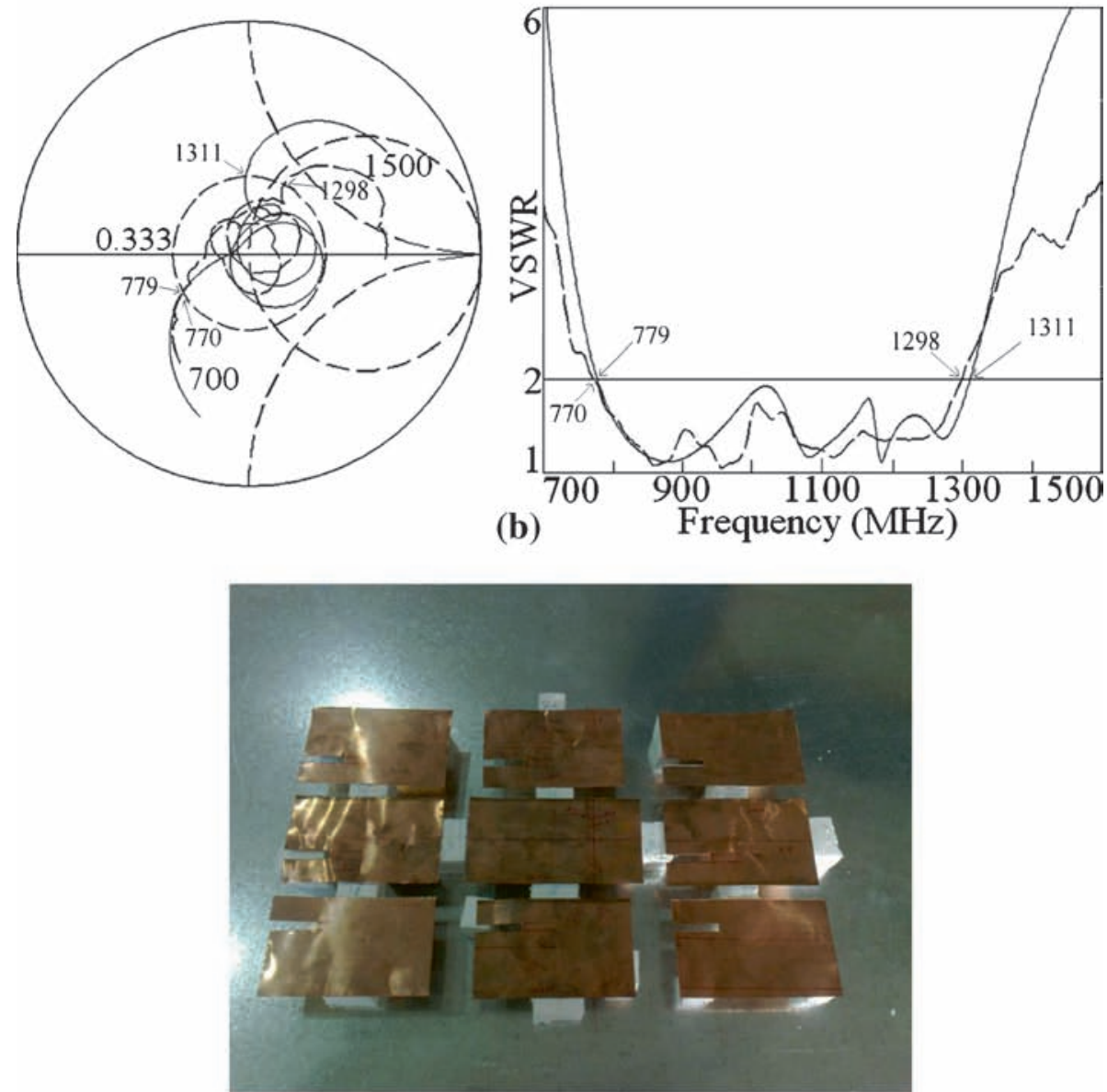

(c)

Figure 7. (a) Proximity fed $3 \times 3$ half E-shaped MSA array, (b) input impedance and VSWR plots, (-) simulated, (- ) measured and (c) fabricated prototype. 
and to improve upon radiation pattern and gain characteristics, half E-shaped MSAs is gapcoupled along all the edges of proximity fed RMSA, as shown in figure 5(a). The slot length in all the parasitic half E-shaped MSAs was kept the same, which realizes same modified $\mathrm{TM}_{01}$ mode resonance frequency. A broader BW is realized by optimizing the spacing between all the MSAs, as shown in figure 5(b). The simulated BW is $514 \mathrm{MHz}(48.5 \%)$ whereas the measured BW is $518 \mathrm{MHz}$ (48\%). The fabricated prototype of the configuration is shown in figure 5(c). Since the slot and parasitic patch dimensions are equal, an increase in the BW is smaller. However, as half E-shaped MSA are gap-coupled along all the edges of proximity fed RMSA, this configuration has better radiation pattern and gain characteristics as shown in figure $6(\mathrm{a}-\mathrm{d})$.

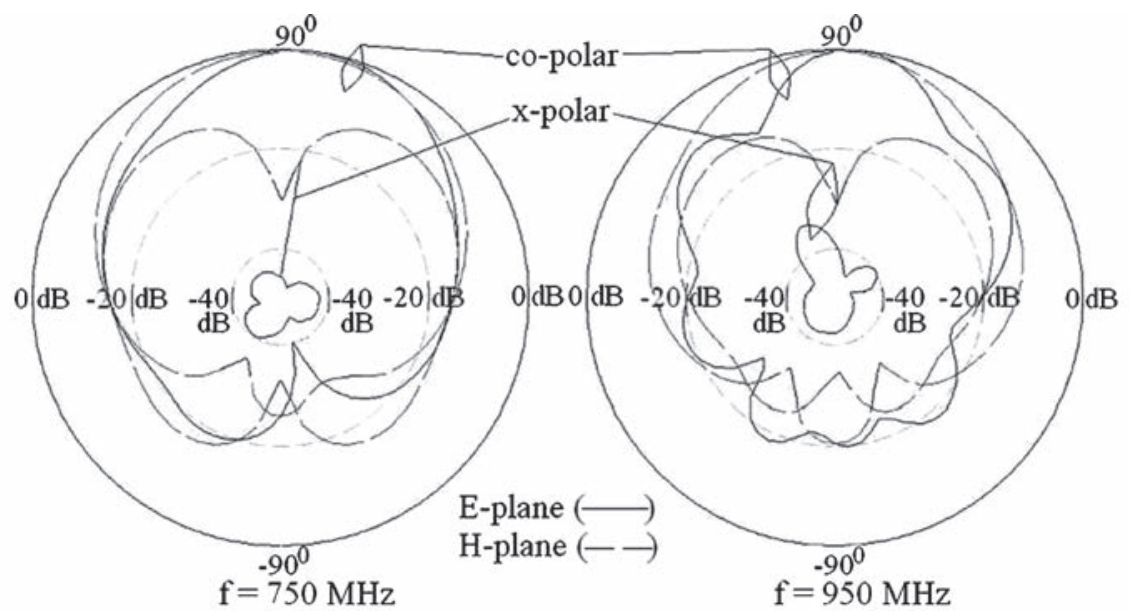

(a)

(b)

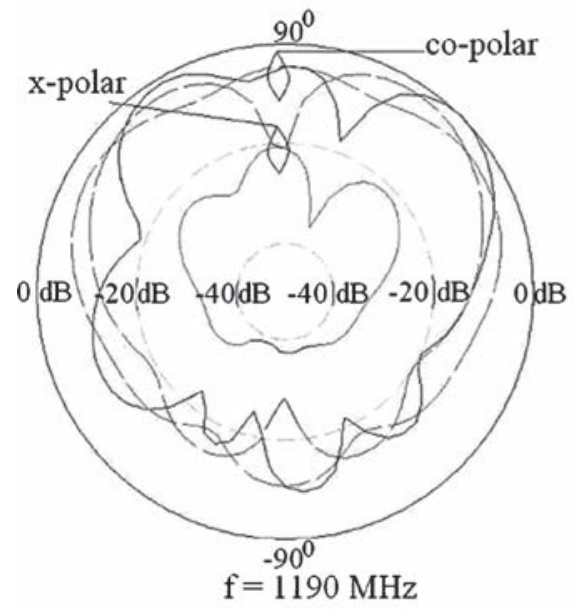

(c)

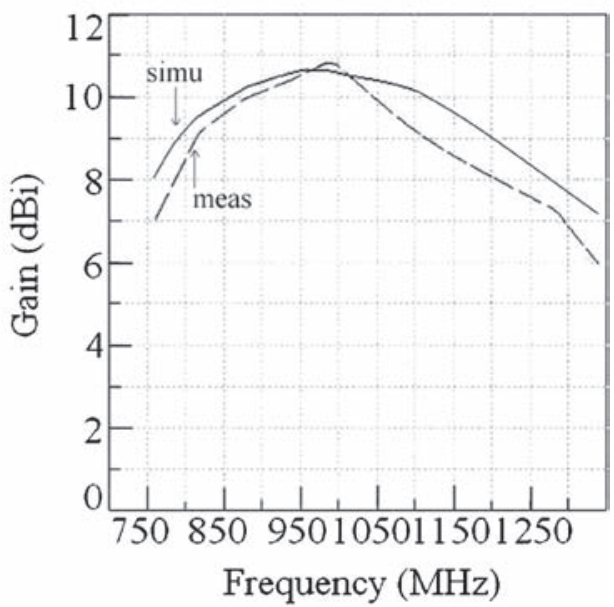

(d)

Figure 8. (a-c) Radiation pattern and (d) gain variation over BW for proximity fed $3 \times 3$ half E-shaped MSA array. 
Table 1. Comparison of various proximity fed gap-coupled RMSAs and half E-shaped MSAs.

\begin{tabular}{lccc}
\hline Configuration of proximity fed & Simulated BW(MHz, \%) & Measured BW(MHz, \%) & Peak gain (dBi) \\
\hline RMSA & 240,24 & $238,23.8$ & 7 \\
Gap-coupled RMSAs & 363,36 & 358,36 & 9.2 \\
RMSAs and half E-shaped MSAs & $490,48.8$ & $502,45.3$ & 9.5 \\
half E-shaped MSAs & $514,48.5$ & 518,48 & 9.8 \\
$3 \times 3$ half E-shaped MSA Array & 532,51 & 528,51 & 11 \\
\hline
\end{tabular}

To further enhance the gain, additional half E-shaped MSAs are gap-coupled along the diagonal axis in the above gap-coupled configuration, thereby realizing $3 \times 3$ array of half E-shaped MSAs as shown in figure 7(a). To avoid the variation in the radiation pattern over the BW, dimensions of half E-shaped MSAs gap-coupled along the diagonal axis were kept the same. By optimizing the spacing, a broader BW as shown in figure 7(b) is obtained. The simulated $\mathrm{BW}$ is $532 \mathrm{MHz}(51 \%)$ whereas the measured BW is $528 \mathrm{MHz}(51 \%)$. The fabricated prototype of the array is shown in figure 7(c). The radiation pattern and gain over the BW are shown in figure $8(\mathrm{a}-\mathrm{d})$. The pattern is in the broadside direction. The back-lobe radiation is less than 10 $\mathrm{dB}$ as compared to the bore sight level. The cross polarization levels increase towards the higher frequencies of the $\mathrm{BW}$ since the modified $\mathrm{TM}_{01}$ mode in all half E-shaped MSAs is present towards those frequencies. The $3 \times 3 \mathrm{MSA}$ array shows peak gain of nearly $11 \mathrm{dBi}$.

The results for all the gap-coupled configurations are given in table 1 . The increase in BW over different gap-coupled configurations to $3 \times 3 \mathrm{MSA}$ array is nearly by $40 \mathrm{MHz}$. This is due to the equal dimensions of parasitic half E-shaped MSAs which give closely spaced $\mathrm{TM}_{10}$ and modified $\mathrm{TM}_{01}$ mode frequencies over proximity fed and gap-coupled MSAs. The higher BW could have been realized for different resonant frequencies (unequal patch dimensions) of respective modes over parasitic MSAs. However, it leads to higher amount of squint in the radiation pattern away from the broadside direction. In gap-coupled half E-shaped MSAs, the cross polarization levels are higher towards higher frequencies of BW. At these frequencies, $\mathrm{TM}_{01}$ mode in half E-shaped MSA is dominant which leads to vertical currents inside the patch that increases cross polar component and also affects the polarization purity in bore sight direction. With unequal dimensions of half E-shaped MSAs, the cross polarization levels will be further higher due to different resonance frequencies of $\mathrm{TM}_{01}$ modes amongst gap-coupled MSAs. With the antenna characteristics like, BW of more than $500 \mathrm{MHz}$ with broadside radiation pattern and gain of more than $7 \mathrm{dBi}$, the proposed configurations can find applications in mobile communication environment in 800 to $1200 \mathrm{MHz}$ frequency band.

\section{Conclusions}

The broadband proximity fed gap-coupled RMSAs are discussed which can give BW of more than $350 \mathrm{MHz}$. Further to increase the BW, gap-coupled array configurations of half E-shaped MSAs with proximity fed RMSA are proposed. The rectangular slot in half E-shaped MSA reduces the resonance frequency of orthogonal $\mathrm{TM}_{01}$ mode in parasitic RMSAs and along with $\mathrm{TM}_{10}$ modes of proximity fed and gap-coupled RMSAs, yields BW of around $500 \mathrm{MHz}$. The slot also modifies the surface current directions at $\mathrm{TM}_{01}$ mode and aligns them in the same direction as that of the currents at $\mathrm{TM}_{10}$ mode. Thereby it gives broadside radiation pattern over the $\mathrm{BW}$ with gain of more than $7 \mathrm{dBi}$. The gap-coupled configuration of four half E-shaped MSAs yields 
better radiation pattern and gain characteristics as against that with two half E-shaped MSAs. Further, $3 \times 3$ gap-coupled array configurations of half E-shaped MSAs with proximity fed RMSA is proposed. It gives BW of more than $530 \mathrm{MHz}(>55 \%)$ with peak gain of nearly 11 $\mathrm{dBi}$. Due to the presence of modified $\mathrm{TM}_{01}$ mode towards higher frequencies of $\mathrm{BW}$, cross polar levels are higher even in bore sight direction. However, they will be of advantage in multi-path propagation environment wherein signal loss due to polarization mismatch can be minimized.

\section{References}

Bhartia B and Bahl I J 1980 Microstrip Antennas. USA: Artech

Chair R, Mak C L, Lee K F, Luk K M and Kishk A A 2005 Miniaturized wide-bandhalf U-slot and half E-shaped patch antennas. IEEE Transactions on Antennas and Propagation 53(8): 2645-2652

Cock R T and Christodoulou C G 1987 Design of a two layer capacitively coupled, microstrip patch antenna element for broadband applications. IEEE Antennas Propag. Soc. Int. Symp. Dig. 2: 936-939

Deshmukh A A and Kumar G 2005 Compact broadband E-shaped microstrip antennas. Electron. Lett. 41(18): 989-990

Deshmukh A A and Ray K P 2013 Analysis of broadband $\Psi$-shaped microstrip antennas. IEEE Magazine on Antennas and Propagation 55(2): 107-123

Garg R, Bhartia P, Bahl I and Ittipiboon A 2001 Microstrip antenna design handbook. USA: Artech House

Guo Y X, Luk K M, Lee K F and Chow Y L 1998 Double U-slot rectangular patch antenna. Electron. Lett. 34: $1805-1806$

Huynh T and Lee K F 1995 Single-layer single-patch wideband microstrip antenna. Electron. Lett. 31(16): $1310-1312$

IE3D 12.0 2000 Zeland Software. Freemont, USA

Kumar G and Ray K P 2003 Broadband Microstrip Antennas. USA: Artech House

Lau K L, Luk K M and Lee K F 2011 Wideband U-slot microstrip patch antenna array. IEE Proc. Microwave Antennas and Propagation 148(1): 41-44

Lee K F, Yang S L S, Kishk A A and Luk K M 2010 The versatile U-slot patch. IEEE Antennas and Propagation Mag. 52(1): 71-88

Wang H, Huang X B and Fang D G 2008 A single layer wideband U-slot Microstrip patch antenna array. IEEE Antennas and Wireless Propagation Lett. 7: 9-12

Weigand S, Huff G H, Pan K H and Bernhard J T 2003 Analysis and design of broadband single layer rectangular U-slot microstrip patch antenna. IEEE Transactions on Antennas and Propagation 51(3): $457-468$

Wong K L 2002 Compact and broadband microstrip antennas. New York, USA: John Wiley \& sons, Inc.

Wong K L and Hsu W H 2001 A broadband rectangular patch antenna with a pair of wide slits. IEEE Transactions on Antennas and Propagation 49: 1345-1347 